\title{
RE-EVALUATION OF CHROMIUM DOPED ALUMINA FOR DOSIMETRIC APPLICATIONS
}

\author{
E. Einbergs*, A. Zolotarjovs, I. Bite, J. Cipa, V. Vitola, \\ K. Laganovska, L. Trinkler \\ Institute of Solid State Physics, University of Latvia, \\ 8 Kengaraga Str., Riga, LV-1063, LATVIA \\ *e-mail: ernestse@cfi.lu.Iv
}

Many medical examinations involve ionizing radiation. Although the range of available dosimeters is rather wide, their linearity and chemical stability are limited. Recently, there has been a growing interest in new, improved dosimetric materials for emerging applications in medicine and other fields, such as sterilisation of consumer goods and medical instruments, irradiation of seeds, chemical agents and others.

One of the classical dosimeters is carbon-doped alumina $\left(\mathrm{Al}_{2} \mathrm{O}_{3}: \mathrm{C}\right)$ - a well-established and widely used material for personal and industrial dosimeter with a range of great properties, such as high sensitivity, wide linearity range and relative ease of production and handling. However, the demand for reliable dosimeters in a high-dose range is still only partially fulfilled, and alumina doped with chromium ions $\left(\mathrm{Al}_{2} \mathrm{O}_{3}: \mathrm{Cr}\right)$ can be a promising candidate.

In this study, we explored alumina doped with chromium porous microparticles synthesized with a sol-gel method as a possible high dose dosimeter and evaluated its thermostimulated luminescence signal, dose response with two irradiation sources and measured long-time fading. It was found that although the TSL signal was quite complex (consisting of two main peaks above room temperature) and the long-term fading was significant (around $50 \%$ in the span of 30 days), with sufficient optimisation the material could be used as a high-dose dosimeter for X-ray and beta irradiation. Wide high dose linearity range, physical and chemical characteristics, as well as low production costs and ease of synthesis make chromium (III) doped alumina a compelling candidate for applicability in various medical and industry fields.

Keywords: Alumina, chromium, dosimetry, sol-gel, $\mathrm{Al}_{2} \mathrm{O}_{3}: \mathrm{Cr}$. 


\section{INTRODUCTION}

Ionizing radiation possesses a widespread applicability ranging from object identification during security checks to non-intrusive tumour passivation. However, irreversible impact on organic matter can occur with the extensive use of ionizing radiation, especially for extended periods of time. Scientific studies have proven that prolonged exposure (accumulation of irradiation) increases the risk of developing harmful tumours or other types of health issues [1]. To reduce the risks of degrading physical well-being of personnel involved in the usage or maintenance of irradiative equipment, the absorbed dose by the staff must be monitored and managed accordingly. Alongside the mentioned applications, dosimeters can be used in other applications, for example, as a means for determining the intensity of an ionizing radiation source or for discovering radiation leakage in order to thicken the shielding around a source.

Alumina-based dosimeters have been a point of interest for many research groups for some time due to a wide sensitivity range, high chemical stability and hardness, comparably low production costs and a stable signal at RT (room temperature). Multiple experiments were performed by Axelrod et al. with the goal of testing various dopants and expecting improved dosimetric properties, and it was discovered that carbon additives vastly improved thermostimulated luminescence (TSL) intensity, sensitivity, and linearity range. Carbon doped alumina $\left(\mathrm{Al}_{2} \mathrm{O}_{3}: \mathrm{C}\right)$, also known as TLD-500, is one of the best and widely used high sensitivity dosimeteric materials that possesses a wide linearity range $(10 \mu \mathrm{Gy}-10 \mathrm{~Gy})$ [2]. Its main application as a TSL and OSL (optically stimulated luminescence) mate- rial is for medicine, such as radiotherapy, radiodiagnosis, and heavy charged particle dosimetry. However, due to the limitations of measurement setups at the time, chromium as an additive was discarded as the output signal was in the "red" region of the spectrum - outside of the peak sensitivity of photomultiplier tubes. Nevertheless, $\mathrm{Al}_{2} \mathrm{O}_{3}: \mathrm{Cr}$ was noted as a good candidate for OSL dosimetry. With recent advances in Sibased sensors, the "red" luminescence can be considered as an advantage; therefore, the $\mathrm{Cr}$ doping should be re-evaluated.

Recent technological advancements have created a demand for high dose dosimetric materials. Nanostructured chromium (III) oxide doped alumina has shown heigh sensitivity to gamma rays ranging from 100 Gy to $20 \mathrm{kGy}$ without achieving saturation [3] and the luminescence during the pulse, and during the subsequent afterglow, are monitored as functions of time. The material under study is $\alpha-\mathrm{Al}_{2} \mathrm{O}_{3}: \mathrm{C}$. Data are presented on the dependence of the OSL intensity on: (i and in crystalline form up to 750 kGy [4]. Material could become ideal for applications involving high doses like irradiation of consumer goods, seeds, chemical agents and medical instruments.

The performance of most materials used for dosimetry applications is mainly governed by the impurity ions in the crystalline lattice coupled with lattice imperfections around them (with a meaningful difference in size or oxidation state compared to host ions). However, for practical applications of a particular material, the linearity range and fading must be explored. Most materials display a corelation between registered TSL or OSL signal and the dose of ionizing radiation they have been exposed to, but few exhibit a first degree (linear) corelation 
in a wide enough region, also known as linearity range. Another factor that should be considered is fading, which largely contributes to host matrix properties and the depth of trap as the bulk of the lost signal can be attributed to phonon discharge, although some secondary effects can increase fading of relatively deep charge carrier traps.

In this article, we explore chromium (III) oxide doped alumina response to beta and $\mathrm{X}$-ray radiation as well as fading over a period, which is typical of personal dosimeters.

\section{EXPERIMENTAL}

\subsection{Materials}

In the synthesis, analytical grade chemicals were used without further purification. Chromium (III) oxide $\left(\mathrm{Cr}_{2} \mathrm{O}_{3}\right)$ and aluminium nitrate nonahydrate $\left(\mathrm{Al}\left(\mathrm{NO}_{3}\right)_{3} \cdot 9 \mathrm{H}_{2} \mathrm{O}\right.$, purity $99.6 \%$, VWR Prolabo Chemicals) were used as starting materials. As chelat- ing and polymerizable agents, ethylene glycol $\left(\mathrm{HO}\left(\mathrm{CH}_{2}\right)_{2} \mathrm{OH}\right.$, purity $\left.99 \%\right)$ and citric acid $\left(\mathrm{C}_{6} \mathrm{H}_{8} \mathrm{O}_{7}\right.$, purity $\left.99.5 \%\right)$ were used and purchased from Sigma Aldrich. Chromium (III) oxide was dissolved using nitric acid $\left(\mathrm{HNO}_{3}\right.$, assay $65 \%$ ) (Sigma Aldrich).

\subsection{Chromium Doped and Undoped Alumina Synthesis}

Undoped and chromium (III) doped alumina samples were synthesised with suspension and gelation (sol-gel) polymerized complex method, analogous to our previous publications [5]. Amount of added chromium (III) oxide ranged from 0 to $1.5 \mathrm{wt} \%$. Mixtures were prepared at 1:1:4 molar ratio (metal ions to citric acid to ethylene gly-

\subsection{Characterisation}

The same samples as in our previous publication [6] were used, which consisted of a pure alpha phase and did not contain any major disruption in the crystalline lattice due to aforementioned chemical stability. Results gathered from EDX (energy-dispersive X-ray spectroscopy) were used to evaluate the presence of $\mathrm{Cr}$ atoms in the structure. SEM (scanning electron microscope) imaging provided information required to conclude that porous microceramics were created. XRL (X-ray luminescence), PL (photoluminescence) and TSL were used for evaluation of optical properties of the sample. Impurity or defect luminescence col). Deionized water was added to create 0.2 molar solution. After obtaining the necessary consistencies, gels were heated in an open oven at $400{ }^{\circ} \mathrm{C}$ for 2 hours. Upon successful elimination of nitric oxide, black powder was formed, which was calcined for 4 hours at $1400{ }^{\circ} \mathrm{C}$. Calcination yielded white powders with a faint pink shade.

was below detection threshold. Luminescence intensity measurements proved to be inconclusive regarding determination of the optimal concentration of $\mathrm{Cr}_{2} \mathrm{O}_{3}$. The highest TSL readout intensity was registered for the sample with $0.2 \mathrm{wt} \%$.

This study focuses on re-evaluation of $\mathrm{Al}_{2} \mathrm{O}_{3}: \mathrm{Cr}$ linearity range and fading over a month without the possibility of UV exposure. Measurements were conducted using Lexsygresearch LMS (Freiberg instruments) with X-ray and beta sources. Beta source (Sr90) provided a dose of $55 \pm 5.5$ $\mathrm{mGy} / \mathrm{s}$ and samples were irradiated from 60 $\mathrm{s}$ to $8.3 \mathrm{~h}$ or from $3.3 \mathrm{~Gy}$ to $1.65 \mathrm{kGy}$. X-ray 
measurements were made with $40 \mathrm{kV}$ and $0.5 \mathrm{~mA}$, tube consisted of a tungsten target, beryllium window and was powered by Spellman MNX50P50/XCC power supply. As multiple samples with slightly varying masses and surface area were prepared, calibration measurements were performed. Between measurements, samples were preheated to remove any previously accumulated dose, irradiated for $1200 \mathrm{~s}$ (with 66 Gy) and repeatedly measured. The highest registered intensity was taken as a baseline and an equalization coefficient was calculated for other samples, which was applied to avoid invalidation based on inconsistency.

SEM and EDS measurements were conducted using SEM Helious 5 UX (Thermo Fisher Scientific) operated at $2 \mathrm{kV}$ during imaging and at $30 \mathrm{kV}$ during an elemental analysis.

\section{RESULTS}

\subsection{SEM and EDS Measurements}

Results of SEM imaging are shown in Fig. 1. Samples consist of a dense ceramiclike structure with the slight porosity occurring through the grains. Multiple surface holes have been observed along grain boundaries. Grains appear to be polycrystalline with crystallite size of around $40 \mathrm{~nm}$ (calculated from the previously conducted XRD measurements using Scherrer equation).

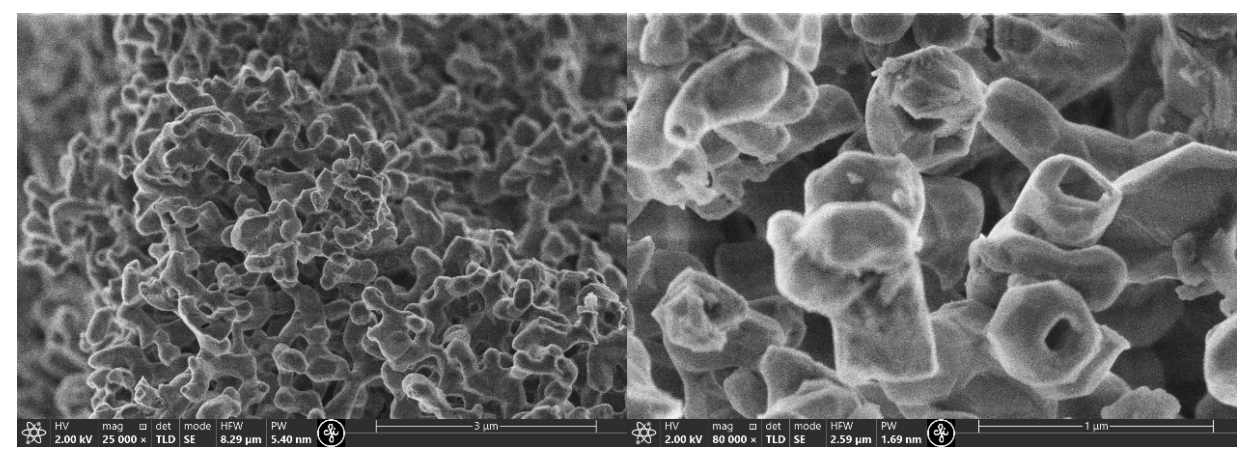

Fig. 1. SEM measurements with varying magnifications.

SEM EDX elemental analysis results are displayed in Fig. 2. The presence of $\mathrm{Cr}$ is confirmed by the corresponding peaks; however, the detection limit of the system forbids accurate evaluation of the absolute concentration value. Negligible amounts of silicon and calcium have been detected originating from different parts of sample synthesis and handling.

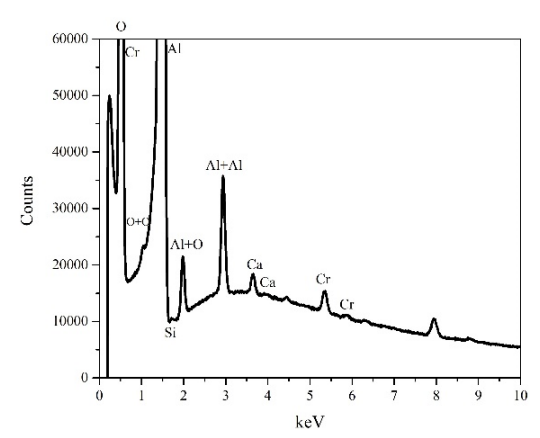

Fig. 2. SEM EDX elemental analysis results. 


\subsection{TSL Measurements}

Samples were pressed into stainless steel (VA 1.4301) discs and measurments were conducted with a 10-minute delay from 20 to $450{ }^{\circ} \mathrm{C}$. Results are shown in Fig. 3. No luminescence signal was registered between 270 and $550 \mathrm{~nm}$.

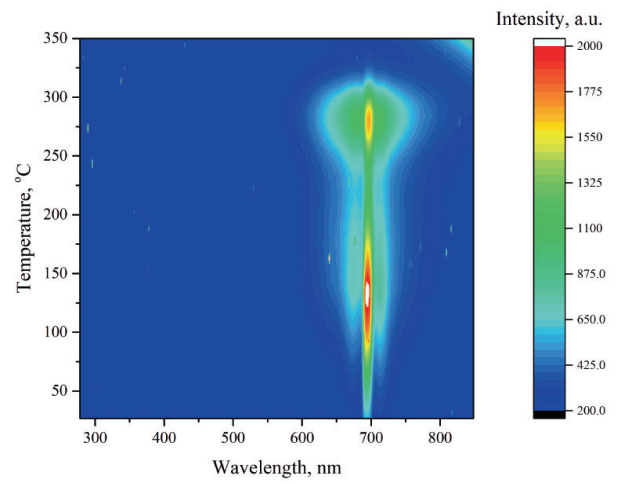

Fig. 3. TSL measurements from 20 to $450{ }^{\circ} \mathrm{C}$ with a 10-minute delay after irradiation.

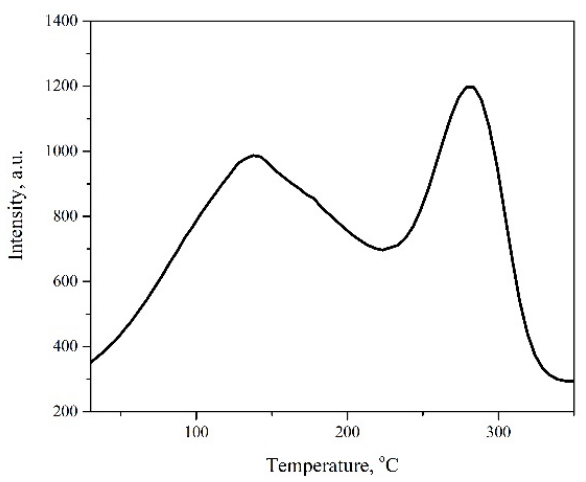

Fig. 4. Relation between the registered TSL intensity and the measured sample temperature heated at $1 \mathrm{~K} / \mathrm{s}$.

\subsection{Dosimetric Properties}

To measure material dose response with regard to different types of irradiation, a series of TSL measurments were performed at different irradiation doses. A 30-minute delay before measurements was implemented to avoid registering sample afterglow. Signal was registered through a quartz window without a slit or a filter.
An example of the registered signal is shown in Fig. 4. Second order approximation summarised in [7] was used to describe the acquired signal (see Fig. 5). Five-peak fit was used and the obtained trap depth energies were as follows: $0.23 \mathrm{eV}$ (1st peak), $0.37 \mathrm{eV}$ (2nd peak), $1.14 \mathrm{eV}$ (3rd peak). All observed glow peaks arise from charge traps at different depths. Peak overlap can contribute to a heating rate, which is enforced by the observations made during fading measurements; over time glow peak intensity fell separately. Peaks are quite direct and one can assume that they could be described adequately with a first-order equation using data from a slower heating rate.

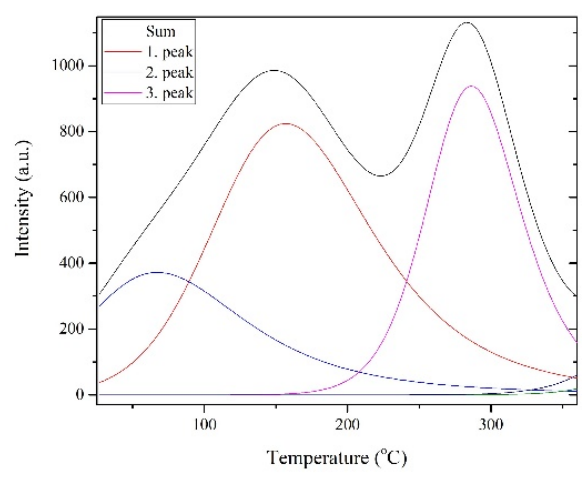

Fig. 5. Results of fitting using Mathematica.

The first $\left(67^{\circ} \mathrm{C}\right)$ and second $\left(157^{\circ} \mathrm{C}\right)$ peaks faded almost completely after 24 hours, which was undesirable for dosimetric applications. The third peak at 286 ${ }^{\circ} \mathrm{C}$ was used to determine the relation between the irradiation dose and the registered TSL signal (see Fig. 6). 


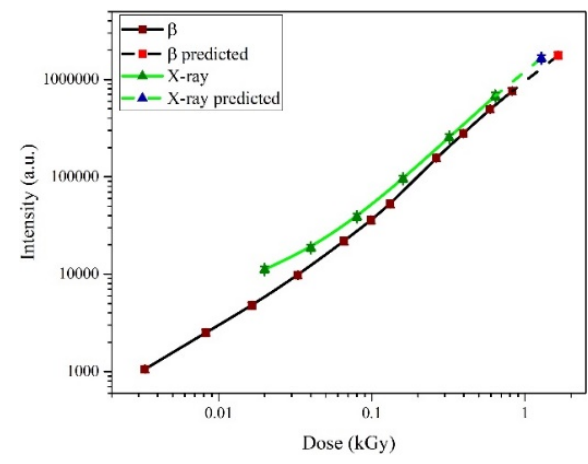

Fig. 6. Relation between the irradiation dose and the registered TSL signal.

Linear fit poorly approximated the relation between the irradiation dose and the registered signal intensity from 3.3 Gy to $1.65 \mathrm{kGy}$ with of 0.86 and reduced ChiSqr of 21.38. Data points were closer represented with a parabolic function with of 0.99 and reduced Chi-Sqr of 0.9. They will be further iterated during discussion.

TSL signal fading was measured up to
31 days. The results are shown in Fig. 7; black points represent the relation between the registered intensity and days elapsed, and red points represent the percentage of charge retained in respect to a measurement preformed right after irradiation. Samples were exposed to $1200 \mathrm{~s}$ (66 Gy) of beta irradiation because it was the midpoint of a logarithmic exposure range.

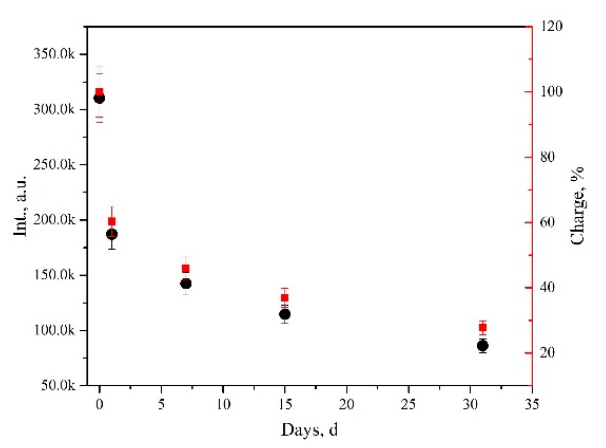

Fig. 7. Relation between days after exposure to beta radiation and the registered TSL signal. Black points represent the measured intensity and red points represent the remaining charge.

\section{DISCUSSION}

Our previous research [6] proposed chromium (III) doped alumina as a good candidate for high dose applications. The aim of this research has been to reproduce the previously acquired results with adequately calibrated equipment and expand using the acquired data. The fact that alumina displays a growing parabolic relation between TSL intensity and the dose it was exposed to only furthers the narrative that chromium doped alumina is a great candidate for high dose dosimetry. Our current equipment forbids substantial and representative exploration of doses above $2 \mathrm{kGy}$, which proved to be insufficient to achieve saturation or a stark transition between linear and supralinear response regions [8], both of which were usually observable.
Measurements with a higher exposure dosage are required to complete a TSL dose response curve.

While exploring TSL signal fading, a rather harsh drop in intensity was observed as peaks at $67{ }^{\circ} \mathrm{C}$ and $157{ }^{\circ} \mathrm{C}$ disappeared almost completely after $24 \mathrm{~h}$. High fading for peak at $67{ }^{\circ} \mathrm{C}$ was expected due to its rather shallow nature. Rapid discharge of the second glow peak could the attributed to charge transfer between traps, which required further study to prove or disprove. Undoubtedly, during irradiation for $16 \mathrm{~h}$, $32 \mathrm{~h}$ and even longer fading would start affecting the TSL signal unpredictably. Usage of stronger beta radiation sources or the determination of discharge rates of $\mathrm{R}_{1}, \mathrm{R}_{2}, \mathrm{~N}$ and chromium clusters is advised 
for further study of the excessive fading. Chromium cluster disintegration due to diffusion is yet to be observed or explored intentionally.
TSL signal reproducibility while using the same sequence and experimental setup was explored. The highest observed intensity deviation was $7.73 \%$.

\section{CONCLUSION}

The conducted study has shown that chromium (III) doped alumina displays a promising dose response for use in highdose applications. Within a margin of error, the material can be used as a linear integral dosimeter from 3.3 to $6.6 \mathrm{~Gy}$ and from 9.9 Gy to $1.65 \mathrm{kGy}$, but saturation was not achieved. A wide high dose linearity range, physical and chemical characteristics, as well as low production costs and ease of synthesis make chromium (III) doped alu- mina a compelling candidate for applicability as a high dose integral dosimetric material.

In future research, the possibility of conducting OSL measurements for dose determination will be explored.

Chromium (III) doped microceramics displays promising features for dosimetric applications but suffers from considerable fading, which is yet to be fully explored.

\section{ACKNOWLEDGEMENTS}

Financial support provided by Scientific Research "Luminescence Mechanisms and Dosimeter Properties in Prospective Nitrides and Oxides Using TL and OSL Methods" LZP FLPP No. LZP-2018/1-0361 implemented at the Institute of Solid State Physics, University of Latvia is greatly acknowledged.
The Institute of Solid State Physics, University of Latvia as the Centre of Excellence has received funding from the European Union's Horizon 2020 Framework Program H2020-WIDESPREAD-01-20162017-TeamingPhase2 under grant agreement No. 739508 , project CAMART ${ }^{2}$.

\section{REFERENCES}

1. Cardis, E., Gilbert, E. S., Carpenter, L., Howe, G., Kato, I. ... \& Lave, C. (2006). Effects of Low Doses and Low Dose Rates of External Ionizing Radiation: Cancer Mortality among Nuclear Industry Workers in Three Countries. Radiation Research, 142 (2), 117-132. https://doi.org/ $10.2307 / 3579020$

2. Akselrod, M.S., Kortov, V.S., Kravetsky, D.J., \& Gotlib, V. I. (1990). Highly Sensitive Thermoluminescent Anion-Defective. $R a$ - diation Protection Dosimetry, 32 (1), 15-20.

3. Markey, B. G., Colyott, L. E., \& Mckeever, S. W. S. (1995). Time-Resolved Optically Stimulated Luminescence from $\alpha-\mathrm{Al}_{2} \mathrm{O}_{3}: \mathrm{C}$. Radiation Measurements, 24 (4), 457-463. https://doi.org/10.1016/1350-4487(94) 00119-L

4. Nikiforov, S. V., \& Kortov, V. S. (2014). Dosimetric Response for Crystalline and Nanostructured Aluminium Oxide to a High-Current Pulse Electron Beam. 
Radiation Protection Dosimetry, 162 (1-2), 92-95. https://doi.org/10.1093/rpd/ncu225

5. Smits, K., Olsteins, D., Zolotarjovs, A., Laganovska, K., Millers, D., Ignatans, R., \& Grabis, J. (2017). Doped Zirconia Phase and Luminescence Dependence on the Nature of Charge Compensation. Scientific Reports, 7 (November 2016), 1-7. https:// doi.org/10.1038/srep44453

6. Einbergs, E., Zolotarjovs, A., Bite, I., Laganovska, K., Auzins, K. ... \& Trinkler, L. (2019). Usability of Cr-Doped Alumina in Dosimetry. Ceramics, 2 (3), 525-535. https://doi.org/10.3390/ceramics2030040

7. Kitis, G., Gomez-Ros, J. M., \& Tuyn, J. W. N. (1998). Thermoluminescence Glow-Curve Deconvolution Functions for First, Second and General Orders of Kinetics. Journal of Physics D: Applied Physics, 31 (19), 2636-2641. https://doi. org/10.1088/0022-3727/31/19/037

8. Horowitz,Y.S.(1984). Thermoluminescence and thermoluminescent dosimetry (Volume 2). CRC Press. 